\title{
PERANCANGAN DAN PEMBUATAN MESIN PENGERING IKAN ASIN TIPE RAK DENGAN KAPASITAS 20KG MENGGUNAKAN BAHAN BAKAR GAS
}

\author{
Rizky Sulvika Puspa Rinda ${ }^{1, a^{*}, \text { Imam }^{2, b}, \text { Pebruana Fitria Sudarni }}{ }^{3, c}$ \\ 1,2 Jl. Cipto Mangunkusumo Kampus Gunung Lipan, Samarinda, Indonesia \\ ${ }^{3}$ JI. Sultan Alimuddin, Samarinda, Indonesia \\ arinda.rizky@polnes.ac.id, bpebruanafitriasudarni17@gmail.com
}

\begin{abstract}
Abstrak
Ikan asin kering merupakan produk olahan pangan yang dalam prosesnya melalui beberapa tahap, diantaranya adalah proses penggaraman dan pengeringan. Proses tersebut dilakukan agar ikan asin dapat bertahan lama. Proses pengeringan dapat dilakukan dengan menjemur ikan yang telah melalui proses penggaraman di bawah sinar matahari langsung. Tetapi proses ini memakan waktu yang relatif lama karena sangat bergantung pada cuaca. Tujuan dari penelitian ini adalah untuk merancang dan membuat mesin pengering ikan asin yang lebih efesien waktu. Metode yang digunakan dalam penelitian ini adalah dengan merancang rangka kemudian mengujicoba mesin dan selanjutnya menganalisis mesin untuk memastikan mesin dapat bekerja dengan baik. Hasil pengujian menunjukan bahwa mesin pengering ikan asin tipe rak dengan kapasitas $20 \mathrm{~kg}$ dapat bekerja maksimal dengan proses pengeringan ikan hanya membutuhkan waktu 6 jam. Mesin pengering ini mampu mengurangi kadar air pada ikan sepat asin dari 55\% menjadi $35,48 \%$. Suhu panas yang baik untuk proses pengeringan ikan sepat asin agar diperoleh hasil pengeringan yang rata dan kering adalah $70^{\circ} \mathrm{C}-80^{\circ} \mathrm{C}$.
\end{abstract}

Kata kunci : Mesin Oven Pengering, Proses Ikan Asin, Kadar Air

\begin{abstract}
Dried salted fish is a processed food product which in the process goes through several stages, including the process of salting and drying. These processes are carried out so that the salted fish do not rot quickly and can last longer. The drying process is done by drying the fish that have gone through the salting process under direct sunlight. However, this process takes a relatively long time because it is highly dependent on the weather. The aim for this research was to design and manufacture a more time efficient salted fish drying machine. The method used in this research was to design the frame then test the machine and also analyze the machine to ensure the machine are able to work properly. The test results showed that the rack-type salted fish drying machine with a capacity of $20 \mathrm{~kg}$ was able to optimally work with the fish drying process only took 6 hours. This drying machine is able to reduce the water content of salted fish from $55 \%$ to $35.48 \%$. It was also suggested that a good heat temperature for the drying process of salted fish in order to obtain an even and dry drying result was at $70^{\circ} \mathrm{C}$ $80^{\circ} \mathrm{C}$
\end{abstract}

Keywords : Drying Oven Machine, Salted Fish Process, Moisture content

\section{PENDAHULUAN}

Ikan asin merupakan makanan khas masyarakat Indonesia. Hampir semua lapisan masyarakat mengkonsumi makanan yang terbuat dari ikan yang diasinkan dan kemudian melalui proses 
pengeringan. Ikan asin yang banyak terdapat di pasaran merupakan hasil produk dari usaha mikro kecil menengah (UMKM). Jika proses pengolahan yaitu dengan teknik penggaraman dan pengeringan tidak dilakukan dengan baik, ikan asin yang dihasilkan dapat rentan mengalami pembusukan.

Di Kota Samarinda sendiri saat ini potensi sumber daya di bidang perikanan masih mengandalkan hasil tangkapan sungai. Perkembangan komoditas unggulan pada dua tahun terakhir yang paling banyak yaitu jenis ikan sepat siam. Keadaan ekonomi sekarang dan pada masa yang akan datang dapat memberikan pengaruh terhadap pengembangan UKM dalam pengolahan ikan sepat asin kering di Kota Samarinda. Melihat dari permintaan pasar yang begitu tinggi terhadap komoditas tersebut sedangkan proses produksi masih bergantung pada hasil pengeringan alami, membuat banyak pengusaha ikan sepat asin kering berupaya keras untuk memenuhi permintaan tersebut.

Proses pengeringan yang dilakukan para produsen ikan sepat asin kering di Kota Samarinda masih menggunakan cara alami yaitu dengan bantuan sinar matahari. Proses ini mempunyai banyak kekurangan diantaranya waktu pengeringan yang lama, memerlukan lokasi yang luas, kualitas ikan akan menurun, gangguan lalat terlebih pada saat musim hujan akan menghambat proses pengeringan. Hal tersebut terjadi karena selama ini belum memadainya teknologi yang tersedia sebagai pendukung pengolahan ikan pasca penangkapan.

Mesin yang dirancang dalam penelitian ini merupakan mesin pengering ikan asin tipe rak yang memiliki kapasitas 20kg dengan menggunakan bahas bakar gas. Desain mesin nantinya akan dilengkapi dengan 4 rak yang di dalamnya mampu menampung $20 \mathrm{~kg}$ ikan basah dan memiliki volume $240.000 \mathrm{~cm}^{3}$. Mesin ini juga akan dilengkapi dengan blower di bagian samping untuk membantu menghembuskan panas agar proses pengeringan dapat berjalan lebih maksimal. Sedangkan pada dinding plat oven diberi paku rivet untuk merapatkan segala sisi agar panas terjaga untuk mempercepat proses pengeringan. Udara panas yang dihembuskan blower yang dihubungkan pada rak pengering bertujuan untuk mempertahankan daya awet dengan cara mengurangi kadar air dan mengurangi berat dan volume ikan.

Penelitian ini bertujuan untuk merancang dan membuat mesin pengering ikan asin yang lebih efesien waktu, dan tentu menghasilkan ikan asin kering yang berkualitas dan bermutu tinggi sehingga dapat memudahkan para produsen ikan asin dalam tahap proses pengeringan ikan.

\section{METODE PENELITIAN}

Proses perancangan pembuatan mesin pengering ikan asin tipe rak dengan kapasitas 20kg menggunakan bahan bakar gas dibagi dalam beberapa tahapan sebagai berikut:

1. Perencanaan rangka oven pengering ikan

2. Perhitungan tegangan yang terjadi pada rangka

3. Perhitungan luas penampang

4. Perhitungan tegangan izin

5. Kapasitas massa pada rak oven

6. Perhitungan pengeringan kadar air pada ikan

7. Perhitungan perpindahan panas pada oven

\section{HASIL DAN PEMBAHASAN}

Dalam penelitian ini, rancangan mesin pengering dimulai dari tahap perancangan mesin, pengukuran plat, pemotongan plat, dan kemudian perakitan mesin. Berikut ini adalah 
perancangan rangka serta komponen mesin yang telah melalui tahapan dan perhitungan untuk menghasilkan mesin oven pengering ikan asin kapasitas 20 $\mathrm{kg}$ menggunakan bahan bakar gas.

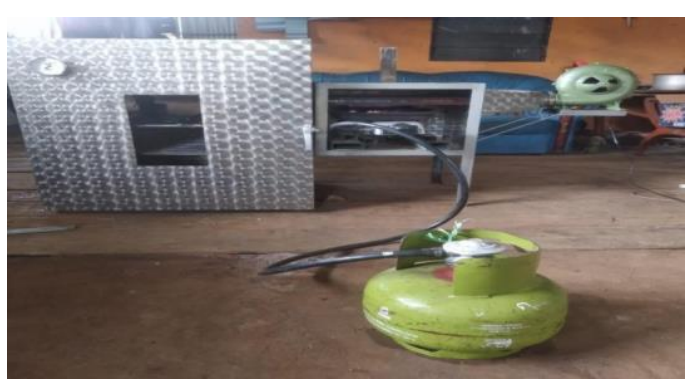

Gambar 1. Mesin pengering tipe rak dengan kapasitas $20 \mathrm{~kg}$

Perhitungan rangka mesin pengering ikan. Data perencanaan rangka yang diketahui dalam perencanaan mesin pengering ikan adalah sebagai berikut :

1. Jenis rangka $=$ Besi Siku / Profil L

2. Ukuran besi siku $=30 \times 30 \times 3 \mathrm{~mm}$

3. Bahan rangka $=\mathrm{ST}-37$

4. Kekuatan Tarik $\left(\sigma_{B}\right)=37 \mathrm{~kg} / \mathrm{mm}$

5 . Beban rencana $(\mathrm{F}) \quad=25 \mathrm{~kg}$

6. Faktor keamanan $(\mathrm{sf})=6,0$

Perhitungan tegangan yang terjadi pada rangka. Untuk mengetahui tegangan yang terjadi pada rangka, maka dilakukan perhitungan sebagai berikut:

$$
\begin{aligned}
\tau & =\frac{\mathrm{F}}{\mathrm{A}} \\
& =\frac{25}{900} \\
& =0,028 \mathrm{~kg} / \mathrm{mm}^{2}
\end{aligned}
$$

Perhitungan tegangan izin. Untuk mengetahui tegangan yang diizinkan pada rangka, maka dilakukan perhitungan sebagai berikut:

$$
\tau_{\mathrm{ijin}}=\frac{\sigma \mathrm{B}}{\mathrm{SF}}
$$

$$
\begin{aligned}
& =\frac{37}{6} \\
& =6,16 \mathrm{~kg} / \mathrm{mm}^{2}
\end{aligned}
$$

Perhitungan luas penampang. Adapun perhitungan luas penampang dengan menggunakan rumus sebagai berikut:

$$
\begin{aligned}
\mathrm{A} & =\mathrm{P} \times \mathrm{L} \\
& =30 \times 30 \\
& =900 \mathrm{~mm}^{2}
\end{aligned}
$$

Dimana: $\tau=$ Tegangan $\left(\mathrm{kg} / \mathrm{mm}^{2}\right)$

$$
\mathrm{A}=\text { Luas Penampang }\left(\mathrm{mm}^{2}\right)
$$$$
\mathrm{F}=\text { Beban Rencana (kg) }
$$$$
\mathrm{P}=\text { Panjang }(\mathrm{mm})
$$$$
\mathrm{L}=\operatorname{Lebar}(\mathrm{mm})
$$

Setelah dilakukan perhitungan, didapat tegangan yang terjadi pada rangka mesin adalah sebesar $0,028 \mathrm{~kg} / \mathrm{mm}^{2}$, dikarenakan tegangan yang terjadi lebih kecil dibandingkan tegangan izinnya $\left(0,028 \mathrm{~kg} / \mathrm{mm}^{2}<6,16 \mathrm{~kg} / \mathrm{mm}^{2}\right)$ maka rangka dapat dikatakan aman untuk digunakan

Kapasitas massa pada rak mesin pengering. Adapun perhitungan kapasitas massa pada rak pengering adalah sebagai berikut:

Massa Ikan $=75$ gram

Luas Rak $=p \times 1=65 \times 65=4225 \mathrm{~cm}^{2}$ Ukuran Ikan $=p \times 1=11 \times 5=55 \mathrm{~cm}^{2}$

$$
\begin{aligned}
\mathrm{Kr} & =\frac{\text { luas rak }}{\text { ukuran }} \\
& =\frac{4225}{55} \\
& =76 \text { ekor } / \mathrm{rak} \\
\mathrm{Tr} & =76 \text { ekor } \times 75 \text { gram } / \text { ekor } \\
& =5,7 \mathrm{~kg} \text { ikan } \\
\mathrm{Rk} & =5,7 \times 4 \\
& =22,8 \mathrm{~kg} \rightarrow 20 \mathrm{~kg}
\end{aligned}
$$

Dimana: $\mathrm{Ma}=$ Massa Ikan

$$
\begin{aligned}
& \mathrm{L}_{\mathrm{R}}=\text { Luas Rak } \\
& \mathrm{U}=\text { Ukuran Ikan }
\end{aligned}
$$


Perhitungan pengeringan kadar air pada ikan. Pengeringan ikan ini untuk mengurangi kadar air awal ikan dari $75 \%$ menjadi $20 \%$ sehingga banyaknya air yang harus di kurangi dalam $20 \mathrm{~kg}$ ikan sepat basah adalah $75 \%-20 \%=55 \%$, sedangkan banyak air yang terkandung dalam $20 \mathrm{~kg}$ ikan sepat basah adalah $55 \% \times 20 \mathrm{~kg}=11$ $\mathrm{kg}$. Maka banyaknya air yang harus dikurangi dalam $20 \mathrm{~kg}$ ikan sepat adalah $55 \% \times 11 \mathrm{~kg}=6,02 \mathrm{~kg}$.

- Perhitungan kadar air awal Adapun perhitungan kadar air awal pada ikan menggunakan persamaan berikut:

$$
\begin{aligned}
\mathrm{M}_{1} & =\left(\mathrm{m}_{a} / \mathrm{m}_{\mathrm{p}}\right) \times 100 \% \\
& =(11 / 20) \times 100 \% \\
& =55 \%
\end{aligned}
$$

- Perhitungan kadar air akhir

Adapun perhitungan kadar air akhir pada ikan menggunakan persamaan berikut:

$$
\begin{aligned}
\mathrm{M}_{2} & =\left[\left(\mathrm{m}_{a}\right) /\left(\mathrm{m}_{a}+\mathrm{m}_{\mathrm{p}}\right)\right] \times 100 \% \quad(6)[5] . \\
& =[(11) /(11+20)] \times 100 \% \\
& =[(11) /(31)] \times 100 \% \\
& =35,48 \%
\end{aligned}
$$

Dimana: $\mathrm{M}_{1}=$ Kadar Air Awal

$\mathrm{M}_{2}=$ Kadar Air Akhir

$\mathrm{M}_{a}=$ Massa Air

$\mathrm{M}_{\mathrm{p}}=$ Massa Padatan

- Perhitungan massa ikan setelah dikeringkan

Dengan menggunakan persamaan berikut, didapatkan berat ikan setelah dikeringkan:

$$
\mathrm{M}_{\mathrm{tk}}=\frac{\left(100-\mathrm{M}_{1}\right)}{100} \times \mathrm{m}_{\mathrm{tb}} \quad \text { (7) [6] }
$$

$$
\begin{aligned}
& =\frac{(100-55)}{100} \times 75 \\
& =33,75 \mathrm{~kg}
\end{aligned}
$$

Dimana: $\mathrm{M}_{\mathrm{t}}=$ Massa Ikan Kering $(\mathrm{kg})$

$\mathrm{M}_{1}=$ Kadar Air Awal Ikan (\%)

$\mathrm{m}_{\mathrm{tb}}=$ Massa Ikan Basah $(\mathrm{kg})$

- Perhitungan massa air yang diuapkan dari bahan

Adapun massa air yang diuapkan ketika proses pengeringan ikan, dihitung menggunakan persamaan berikut:

$$
\begin{aligned}
M_{\mathrm{w}} & =\frac{100\left(\mathrm{M}_{1}-\mathrm{M}_{2}\right)}{\left(100-\mathrm{M}_{1}\right)\left(100-\mathrm{M}_{2}\right)} \times \mathrm{m}_{\mathrm{tk}}(8)[5] . \\
& =\frac{100(55-35,48)}{(100-55)(100-35,48)} \times 33,75 \\
& =0,10 \mathrm{~kg}
\end{aligned}
$$

$$
\begin{aligned}
& \text { Dimana: } \mathrm{M}_{1}=\text { Kadar Air Awal Ikan (\%) } \\
& \mathbf{M}_{2}=\text { Kadar Air Akhir Ikan (\%) } \\
& \mathrm{M}_{\mathrm{tk}}=\text { Massa Akhir Ikan (kg) }
\end{aligned}
$$

Perhitungan perpindahan panas pada mesin pengering ikan asin. Perpindahan panas secara radiasi adalah perpindahan panas tanpa zat perantaranya, dan dapat terjadi pada gas dan ruang hampa udara. Adapun perhitungan perpindahan panas pada mesin pengering dihitung menggunakan persamaan berikut:

Luas Penampang Plat $=4000 \mathrm{~cm}^{2}=0,4 \mathrm{~m}^{2}$

Suhu Akhir Plat $\quad=80^{\circ} \mathrm{C}+273=358 \mathrm{~K}$

Emisivitas Bahan $=0,9$

Tetapan Boltzman $=\sigma=5,67 \times 10^{-8} \mathrm{~W} / \mathrm{m}^{2} \mathrm{~K}^{4}$

$$
\mathrm{Q}=\mathrm{e} \sigma \mathrm{A} \mathrm{T}^{4}
$$

$$
\begin{aligned}
& =(0,9)\left(5,67 \times 10^{-8} \mathrm{~W} / \mathrm{m}^{2} \mathrm{~K}^{4}\right)(0,4) \\
& (358)^{4} \\
& =(0,9)\left(5,67 \times 10^{-8}\right)(0,4)(1,64 \times \\
& \left.10^{10}\right) \\
& =334,7568 \mathrm{~W}
\end{aligned}
$$

Dimana:

$\mathrm{P}=$ Daya Yang Diradiasikan (watt)

$\mathrm{A}=$ Luas Suatu Benda yang 
Memancarkan Radiasi $\left(\mathrm{m}^{2}\right)$

$\mathrm{T}=$ Suhu Mutlak (K)

$\mathrm{E}=$ Emisivitas Bahan

$\sigma=$ Konstanta Stefan $\left(5,6703 \times 10^{-8}\right.$

$\mathrm{W} / \mathrm{m}^{2} \mathrm{~K}^{4}$ )

- Kebutuhan energi pengeringan

Dalam proses pengeringan, energy yang dibutuhkan dihitung menggunakan persamaan berikut:

Massa air yang di uapkan dari ikan = 0,06 gram

Waktu pengeringan $=6 \mathrm{Jam}: 21.600 \mathrm{~s}$

Panas laten penguapan $(\mathrm{kJ} / \mathrm{kg})$ panas laten untuk ikan sepat $=2558,73 \mathrm{~kJ} / \mathrm{kg}$.

$$
\begin{aligned}
Q_{b} & =\frac{M_{w}}{t} \times L_{h} \\
& =\frac{0,06}{21600} \times 2558,73 \\
& =0,00710 \mathrm{~kJ} / \mathrm{s} \\
& =7,10 \mathrm{~J} / \mathrm{s}
\end{aligned}
$$

Dimana:

$\mathrm{Q}_{\mathrm{b}}=$ panas yang dibutuhkan untuk mengeringkan bahan $(\mathrm{J} / \mathrm{s})$

$\mathrm{M}_{\mathrm{w}}=$ massa air yang diuapkan dari bahan $(\mathrm{kg})$

$\mathrm{T}=$ waktu pengeringan (detik)

$\mathrm{L}_{\mathrm{h}}=$ panas penguap $(\mathrm{kJ} / \mathrm{kg})$

Hasil pengujian mesin. Mesin pengering ikan asin tipe rak berkapasitas $20 \mathrm{~kg}$ harus melalui tahap pengujian untuk memastikan bahwa kinerja dari masing-masing komponen mesin pengering ikan dapat berfungsi dengan baik. Pengujian dilakukan untuk mengetahui hasil pada ikan yang akan dikeringkan dan perpindahan panas (radiasi) dengan melalui media udara panas yang memiliki ruang. Alat dan bahan yang digunakan antara lain, mesin pengering, pisau, telanan, timbangan, baskom, ikan sepat dan gas LPG. Setelah mempersiapkan mesin dan bahan, langkah selanjutnya adalah membersihkan ikan dari darah dan kotoran dengan air hingga bersih.
Kemudian mempersiapkan larutan garam sebanyak 5\% untuk merendam ikan. Perendaman di lakukan selama 3 jam dalam wadah tertutup. Selanjutnya cuci kembali ikan dengan air bersih dan tiriskan. Setelah itu susun ikan di atas rak mesin pengering yang sudah di siapkan agar bisa langsung di lakukan proses pengeringan di dalam mesin pengering.

Pengujian dilakukan tiga kali. Pengujian pertama dilakukan dengan menggunakan $10 \mathrm{~kg}$ ikan sepat dengan masa pengeringan selama 2 jam dan suhu normal awal $40^{\circ} \mathrm{C}$ menggunakan api sedang. Rad55077mekJt/kgertama ikan mengalami perubahan warna dan kandungan air mulai terserap. Kemudian pada menit ke-60, api ditingkatkan menjadi maksimal dan suhu oven meningkat menjadi $66^{\circ} \mathrm{C}$. Pada suhu tersebut, ikan di bagian rak paling bawah tampak mongering. Kemudian pada menih ke-90 suhu kembali naik sampai $78^{\circ} \mathrm{C}$. Setelah 120 menit, suhu menjadi stabil paa $78^{\circ} \mathrm{C}-$ $80^{\circ} \mathrm{C}$ dengan keadaan ikan setengah kering karena daging ikan terlalu tebal.

Pengujian kedua dilakukan dengan waktu yang sama, yaitu 2 jam dan ikan mengalami pengerutan pada daging dan jamur semakin timbul di permukaan daging ikan. Pada proses uji kedua ini daging ikan sudah mengering merata dengan baik.

Pengujian ketiga dilakukan untuk menyempurnakan proses pengeringan. Waktu yang sama, yaitu 2 jam, ikan sudah terlihat kering dengan sempurna warna yang dihasilkan terlihat kecoklatan. Dengan demikian dapat simpulkan bahwa mesin pengering dapat bekerja maksimal dengan waktu pengeringan selama 6 jam.

Hasil analisa mesin. Analisa mesin dilakukan untuk melihat perubahan kadar air pada ikan, perubahan suhu dan waku pengeringan. 
Tabel 1. Perubahan Kadar Air Ikan dan Waktu Pengeringan

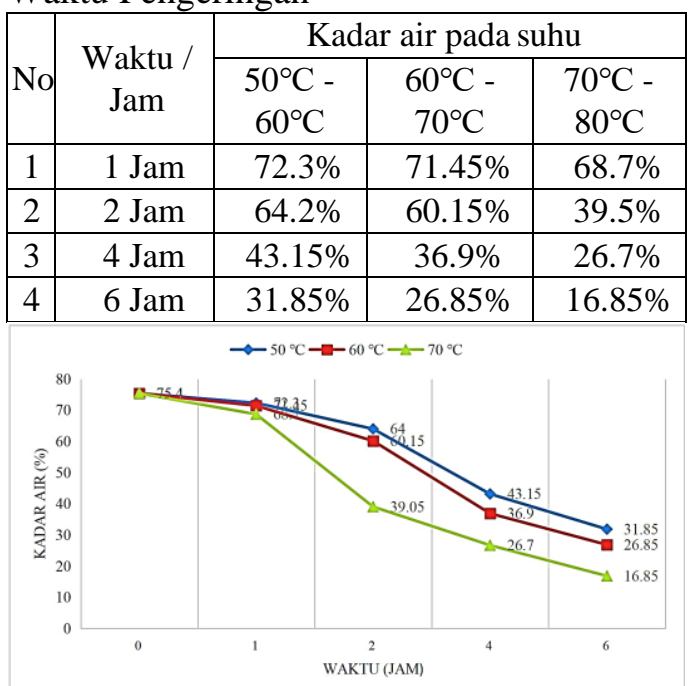

Grafik 1. Perubahan Kadar Air Ikan dan Waktu Pengeringan

Dari Tabel 1. menunjukkan bahwa nilai kadar air ikan sepat siam segar yaitu $75,4 \%$. Setelah dilakukan proses pengeringan selama 1 jam menunjukan nilai kadar air pada suhu $50^{\circ} \mathrm{C}$ sebesar $72,3 \%$. Pada suhu $60^{\circ} \mathrm{C}$ sebesar $71,45 \%$ dan pada suhu $70^{\circ} \mathrm{C}$ sebesar $68,70 \%$. Hal ini menunjukan bahwa kadar air terendah pada suhu $70^{\circ} \mathrm{C}$, penurunan nilai kadar air ini akan terus berkurang dengan semakin lamanya waktu yang digunakan selama proses pengeringan hingga waktu 6 jam. Pada Grafik 1 . terlikat bahwa dalam proses pengeringan menggunakan mesin oven dalam waktu 6 jam dengan suhu mencapai $80^{\circ} \mathrm{C}$, kadar air pada ikan sepat asin tuhun hingga 16,86\%.

Tabel 2. Perubahan Suhu dan Waktu Pengeringan

\begin{tabular}{|c|c|c|c|c|}
\hline No & $\begin{array}{c}\text { Waktu / } \\
\text { Menit }\end{array}$ & $\begin{array}{c}\text { Api } \\
\text { Kecil }\end{array}$ & $\begin{array}{c}\text { Api } \\
\text { Sedang }\end{array}$ & $\begin{array}{c}\text { Api } \\
\text { Besar }\end{array}$ \\
\hline 1 & 20 Menit & $40^{\circ} \mathrm{C}$ & $40^{\circ} \mathrm{C}$ & $40^{\circ} \mathrm{C}$ \\
\hline 2 & 40 Menit & $46^{\circ} \mathrm{C}$ & $62^{\circ} \mathrm{C}$ & $66^{\circ} \mathrm{C}$ \\
\hline 3 & 60 Menit & $46^{\circ} \mathrm{C}$ & $69^{\circ} \mathrm{C}$ & $75^{\circ} \mathrm{C}$ \\
\hline 4 & 80 Menit & $46^{\circ} \mathrm{C}$ & $69^{\circ} \mathrm{C}$ & $80^{\circ} \mathrm{C}$ \\
\hline 5 & 100 Menit & $46^{\circ} \mathrm{C}$ & $69^{\circ} \mathrm{C}$ & $80^{\circ} \mathrm{C}$ \\
\hline 6 & 120 Menit & $46^{\circ} \mathrm{C}$ & $69^{\circ} \mathrm{C}$ & $80^{\circ} \mathrm{C}$ \\
\hline
\end{tabular}

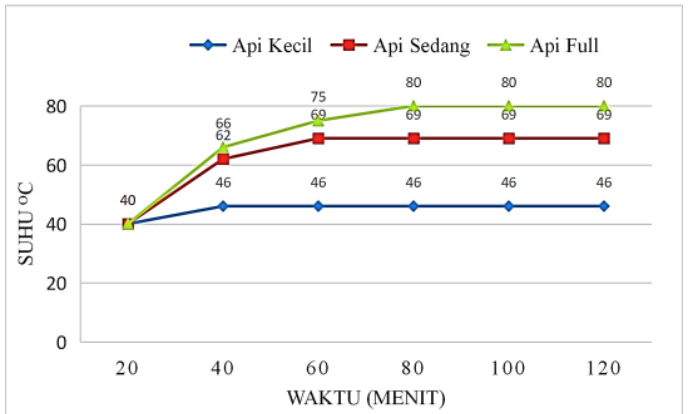

Grafik 2. Perubahan Suhu dan Waktu Pengeringan

Tabel 2. menunjukkan bahwa pada pengujian pertama, dengan menggunakan api kecil, pada 20 menit pertama suhu normal oven yaitu $40^{\circ} \mathrm{C}$ dan pada menit ke-40 suhu naik menjadi $46^{\circ} \mathrm{C}$ dan tidak meningkat sampai menit ke-120. Kemudian pada pengujian kedua, pada 20 menit pertama dengan menggunakan api sedang, suhu berada di $40^{\circ} \mathrm{C}$ dan pada menit ke 40 suhu naik menjadi $62^{\circ} \mathrm{C}$ dan pada menit ke-60 suhu kembali naik menjadi $69^{\circ} \mathrm{C}$ dan sampai akhir proses pengeringan suhu tidak lagi mengalami kenaikan. Pada pengujian ketiga, dengan menggunakan api besar, suhu oven naik menjadi $40^{\circ} \mathrm{C}$ setelah 20 menit pertama. Pada 40 menit selanjutnya suhu naik menjadi $66^{\circ} \mathrm{C}$ dan pada menit ke-60 suhu kembali meningkat menjadi $75^{\circ} \mathrm{C}$. Kemudian pada menit ke-80 suhu kembali meningkat menjadi $80^{\circ} \mathrm{C}$ dan suhu oven stabil sampai waktu pengeringan selesai. Pada Grafik 2. menunjukkan bahwa pada suhu $75^{\circ} \mathrm{C}-$ $80^{\circ} \mathrm{C}$ proses pengeringan ikan dapat dilakukan dan merupakan suhu yang baik untuk proses pengeringan ikan asin, karena jika suhu melebihi angka $80^{\circ} \mathrm{C}$ maka ikan akan menjadi matang bukan menjadi kering.

\section{KESIMPULAN}

Dari hasil pengujian dan analisis mesin pengering ikan asin tipe rak dengan kapasitas $20 \mathrm{~kg}$, temperatur yang bagus untuk mengeringkan ikan adalah tidak kurang dari $70^{\circ} \mathrm{C}$ dan tidak lebih 
dari $80^{\circ} \mathrm{C}$ karena jika dibawah $70^{\circ} \mathrm{C}$ ikan tidak dapat mongering secara merata dan sempurna. Sedangkan jika di atas $80^{\circ} \mathrm{C}$ ikan menjadi matang, tidak mongering. Proses pengeringan ikan asin hanya membutuh waktu 6 jam lebih cepat dibandingkan pengeringan di jemur di bawah matahari yang membutuhkan waktu sampai 3 hari.

Sedangkan dari hasil perhitungan kadar air yang terkandung dalam ikan asin maka, dapat diambil kesimpulan bahwa kadar air awal ikan adalah 55\%. Kemudian setelah dikeringkan, kadar air akhir ikan menjadi 35,48\%. Massa ikan setelah dikeringkan menyusut hingga $8,95 \%$, dengan massa air yang diuapkan dari ikan sepat selama proses pengeringan adalah $0,02 \mathrm{~kg}$ dan kebutuhan energi panas untuk proses pengeringkan adalah $7,10 \mathrm{~J} / \mathrm{s}$.

Untuk proses pengeringan selama 6 jam, diperlukan 2 tabung gas LPG dengan berat masing-masing $3 \mathrm{~kg}$. Hal ini dapat menjadi pertimbangan bagi produsen sebagai biaya produksi mengingat penggunaan mesin pengering ikan asin ini mampu menghemat efisiensi waktu pengeringan dan mampu menambah hasil produksi. Pemakaian mesin pengering ini masih terbatas pada pemakaian untuk proses pengeringan. Disarankan pula untuk tidak melakukan pengeringan ikan melebihi batas yang sudah ditentukan.

\section{REFERENSI}

[1] Simanjuntak, "Analisis Kadar Formalin pada Ikan Asin yang di Pasarkan di Kota Gorontalo," Universitas Negeri Gorontalo, 2012.

[2] S. Antoni, "Analisa kandungan formalin pada ikan asin dengan metoda spektrofotometri di Kecamatan Tampan Pekanbaru," Universitas Islam Negeri Sultan Syarif Kasim Riau, 2010.

[3] N. F. Sophyan, "Rancang Bangun Alat Pengering Ikan Tipe
Rak Menggunakan Kolektor Surya," Universitas Islam Negeri Alauddin Makassar, 2016.

[4] P. M. Ferguson, B. Susanto, and K. Setianto, Dasar-Dasar Beton Bertulang. Jakarta: Penerbit Erlangga, 1984.

[5] Suharto, Teknologi pengawetan Pangan. Jakarta: Rineka Cipta, 1991.

[6] Joeswadi, Alat Pengering Ikan. Medan: BPPI Medan, 1986.

[7] D. R. Pitts, Teori dan soal-soal perpindahan kalor. Jakarta: Penerbit Erlangga, 1987. 